\title{
AQUISIÇÃO POR COMPANHIAS ABERTAS DE AÇÕES DE SUA PRÓPRIA EMISSÃO
}

Dissertação de Mestrado apresentada ao departamento de Direito Comercial da Faculdade de Direito da Universidade de São Paulo para a obtenção do grau de mestre em direito, sob a orientação do Professor Dr. Marcos Paulo de Almeida Salles.

Faculdade de Direito da Universidade de São Paulo

São Paulo

2013 


\section{Resumo}

A aquisição por companhias abertas de ações de sua própria emissão no Brasil constitui o núcleo de estudo desta dissertação. Também referida como recompra de ações, trata-se de operação comumente realizada por sociedades anônimas, principalmente por companhias abertas, tendo em vista os possíveis benefícios na organização da estrutura de capital da companhia, conciliados com a variedade de motivações para sua utilização.

O trabalho aborda, inicialmente, o tratamento legal conferido às operações realizadas por companhias abertas e fechadas, em especial pela Lei $\mathrm{n}^{0} 6.404$, de 15 de dezembro de 1976. Além da definição das operações e sua evolução legislativa, são analisadas as principais causas que levam uma sociedade anônima a adquirir ações de sua própria emissão, assim como os negócios jurídicos passíveis de realização para que uma aquisição se concretize, além do aproveitamento a ser conferido pela companhia para as ações recompradas - quando estas não forem canceladas, poderão ser mantidas em tesouraria na qualidade de bens de titularidade da companhia.

O estudo também dedica-se à análise específica da aquisição de ações de emissão própria por companhias abertas, sob o foco do regramento expedido pela Comissão de Valores Mobiliários - CVM. Além dos atos normativos emanados pela autarquia, a análise enfatiza os principais interesses a serem tutelados nas operações, assim como aborda precedentes da CVM sobre o tema.

Palavras-Chave: negociação com as próprias ações; aquisição de ações; recompra de ações; manutenção do capital social; intangibilidade do capital social; condições artificiais de demanda, oferta ou preço das ações; práticas não equitativas. 


\begin{abstract}
The purchase, by publicly-held companies, of its own shares in Brazil constitutes the core area of study of this dissertation. Also referred to as stock repurchase, it consists in a transaction commonly performed by corporations, mainly the publicly traded, seeking out the benefits to the organization of the company's capital structure, combined with the variety of motivations for its use.
\end{abstract}

This work initially discusses the legal treatment for stock repurchases performed by publicly-held and closely held companies, in particular by Law 6404, of December $15^{\text {th }}, 1976$. In addition to the definition of the transaction, and its legal developments, this study analyzes the main causes for a corporation to buy its own shares, as well as the legal act of the acquisition per se, and the use of the repurchased shares- whenever they are not canceled, such shares will be held in treasury as assets owned by the company.

The study also presents the repurchase made by publicly-held companies in view of the rules issued by the Comissão de Valores Mobiliários - CVM (the Brazilian Securities and Exchange Commission). Apart from examining CVM's regulation, the study refers to a broad variety of cases decided by CVM on the subject, and investigates the main interests involved on the transactions.

KEYWORDS: negotiation with its own shares; acquisition of shares; stock repurchases; capital maintenance; intangibility of capital; artificial demand, supply or price of shares; unfair practices. 


\section{Introdução}

\section{I.1. Considerações iniciais}

As sociedades anônimas não podem negociar com ações de sua própria emissão, e a Lei das S.A. foi expressa ao estabelecer tal proibição no caput de seu art. 30. Esta vedação, no entanto, não é absoluta, tendo em vista que o $§ 1^{\circ}$ do mesmo artigo lista as exceções ao impedimento de caráter geral. Não se encontram, pois, abrangidas pela vedação à negociação (i) as operações de resgate, reembolso ou amortização (art. 30, $\S 1^{\circ}$, alínea "a"); (ii) a aquisição onerosa de ações de própria emissão para a permanência em tesouraria ou cancelamento, desde que até o valor do saldo de lucros ou reservas, exceto a legal, e sem diminuição do capital social (art. 30, §1, alínea "b"); (iii) a aquisição por doação, também para a permanência em tesouraria ou cancelamento (art. 30, $\S 1^{\circ}$, alínea “b”); (iv) a alienação das ações adquiridas na forma dos itens (ii) e (iii) acima (art. 30, $\S 1^{\circ}$, alínea "c"); e (v) a compra, caso o preço das ações em bolsa for inferior ou igual à importância a ser devolvida em dinheiro através de redução de capital social (art. 30, $\S 1^{\circ}$, alínea “d”) ${ }^{1}$.

O presente trabalho pretende analisar as operações de aquisição de ações de emissão própria realizadas em especial por companhias abertas ${ }^{2}$ para cancelamento ou manutenção em tesouraria, prevista na alínea "b" do $\S 1^{\circ}$ do art. 30 da Lei das S.A. em exceção à regra geral da proibição à negociação, assim como seus respectivos efeitos.

\footnotetext{
${ }^{1}$ Art. 30. A companhia não poderá negociar com as próprias ações.

$\S 1^{\circ}$ Nessa proibição não se compreendem:

a) as operações de resgate, reembolso ou amortização previstas em lei;

b) a aquisição, para permanência em tesouraria ou cancelamento, desde que até o valor do saldo de lucros ou reservas, exceto a legal, e sem diminuição do capital social, ou por doação;

c) a alienação das ações adquiridas nos termos da alínea $b$ e mantidas em tesouraria;

d) a compra quando, resolvida a redução do capital mediante restituição, em dinheiro, de parte do valor das ações, o preço destas em bolsa for inferior ou igual à importância que deve ser restituída.

$\S 2^{\circ} \mathrm{A}$ aquisição das próprias ações pela companhia aberta obedecerá, sob pena de nulidade, às normas expedidas pela Comissão de Valores Mobiliários, que poderá subordiná-la à prévia autorização em cada caso.

$\S 3^{\circ}$ A companhia não poderá receber em garantia as próprias ações, salvo para assegurar a gestão dos seus administradores.

$\S 4^{\circ}$ As ações adquiridas nos termos da alínea $\mathrm{b}$ do $\S 1^{\circ}$, enquanto mantidas em tesouraria, não terão direito a dividendo nem a voto.

$\S 5^{\circ}$ No caso da alínea d do $\S 1^{\circ}$, as ações adquiridas serão retiradas definitivamente de circulação.

${ }^{2}$ Nos termos do art. $4^{\circ}$ da Lei das S.A., "a companhia é aberta ou fechada conforme os valores mobiliários de sua emissão estejam ou não admitidos à negociação no mercado de valores mobiliários".
} 
A aquisição de ações de emissão própria por sociedades anônimas, também conhecida como recompra de ações ${ }^{3}$, foi permitida para as companhias brasileiras de capital autorizado desde $1965^{4}$ e, a partir de 1976, com a promulgação da Lei das S.A., para todas as companhias. É possível que a operação de recompra de ações cause estranheza à primeira vista, pois resultará em uma sociedade anônima possuir suas próprias ações, o que parece ser um contra-senso. No entanto, trata-se de operação bastante relevante para as companhias, principalmente as abertas, tendo em vista a variedade de motivações que levam a sua realização.

Como esclareceu a Exposição de Motivos da Lei das S.A., o legislador de 1976 teve como principal preocupação a manutenção do capital social ao estipular as exceções à negociação com ações de emissão própria pela sociedade anônima. Para os autores do anteprojeto da Lei das S.A., "a lei proíbe a negociação com as próprias ações para proteger a integridade do capital social. Não há razão para manter essa proibição nos casos em que as ações são adquiridas sem prejuízo do capital social e da reserva legal" 5 .

Ao destacar a integridade do capital social, a Lei das S.A. procurou, principalmente, resguardar os credores sociais, tendo em vista considerar o capital social uma segurança para os credores da companhia. No entanto, como pretendemos demonstrar no presente trabalho, a operação de recompra de ações não afeta apenas os interesses dos credores mas, acima de tudo, os interesses da companhia, além dos interesses dos acionistas, dos investidores, bem como dos administradores, empregados e comunidades em que a companhia atue.

Previamente ao exame dos interesses envolvidos nas operações, pretendemos analisar as regras aplicáveis a todas as espécies de companhias (abertas e fechadas), através do estudo das disposições constantes na Lei das S.A. relacionadas às operações

\footnotetext{
${ }^{3} \mathrm{O}$ termo recompra será utilizado ao longo do presente trabalho para referir-se à aquisição, onerosa ou gratuita, de ações de emissão própria por sociedades anônimas.

${ }^{4}$ A Lei $\mathrm{n}^{\circ} 4.728$, de 14 de julho de 1965 (art. 47), que pela primeira vez disciplinou o mercado de capitais no Brasil, permitiu que as sociedades anônimas de capital autorizado adquirissem suas próprias ações mediante a aplicação de lucros acumulados ou capital excedente, e sem redução do capital subscrito.

${ }^{5}$ Lamy Filho, Alfredo. Pedreira. José Luiz Bulhões, “A Lei das S.A.”. Vol. I. Rio de Janeiro: Renovar. 1997. p. 228.
} 
de recompra de ações. Em seguida, o estudo enfatizará a realização das operações por companhias abertas, considerando que a Lei das S.A. (art. 30, §2) e a Lei $n^{\circ} 6.385 / 76^{6}$ (art. 22, § 1, inciso III) atribuíram à CVM competência para normatizar a aquisição das próprias ações por tais companhias. Esta competência foi exercida através da expedição da Instrução CVM n ${ }^{0} 10 / 80^{7}$, que "dispõe sobre a aquisição por companhias abertas de ações de sua própria emissão, para cancelamento ou permanência em tesouraria, $e$ respectiva alienação" e, posteriormente, por Instruções que trataram da negociação com opções lastreadas em ações de sua própria emissão por sociedades anônimas, estando atualmente em vigor a Instrução $\mathrm{CVM} \mathrm{n}^{\circ} 390 / 03^{8}$, a regular as operações aquisitivas.

A peculiaridade e a importância das operações de recompra de ações podem ser evidenciadas tanto pelo cuidado do legislador ao tratar do tema, como pelas estritas condições impostas para a sua realização por todas as companhias, principalmente as abertas. Neste sentido, além da vedação inicial para que as companhias negociem com suas próprias ações, destacamos as restrições aplicáveis a grande parte dos direitos das ações mantidas em tesouraria, a tipificação penal da conduta dos administradores que negociarem indevidamente, por conta da companhia, com as ações por ela emitidas, e a nulidade das operações efetuadas por companhias abertas que não observarem as normas expedidas pela CVM.

O presente estudo será dividido em seis capítulos, sendo o primeiro esta introdução, através da qual faremos nossas observações iniciais, assim como apresentaremos a justificativa para a escolha do tema. Também na introdução delimitaremos a abrangência do presente trabalho, passando pela aparente vedação total contida no art. 30 da Lei das S.A., assim como por um breve panorama das demais operações que, apesar de não estarem em nosso objeto de estudo, são também exceções ao comando geral de proibição da companhia negociar com suas próprias ações.

\footnotetext{
${ }^{6}$ Trata-se da lei que criou a CVM e regulou o mercado de capitais, revogando parcialmente a Lei $n^{\circ}$ 4.728, de 14 de julho de 1965.

${ }^{7}$ Alterada pela Instrução CVM n ${ }^{\circ} 100$, de 13 de junho de 1989, Instrução CVM n ${ }^{0} 111$, de 11 de janeiro de 1980, Instrução CVM n ${ }^{\circ}$ 268, de 13 de novembro de 1997 e pela Instrução CVM n ${ }^{\circ} 390$, de 8 de julho de 2003.

${ }^{8}$ A Instrução CVM n ${ }^{0}$ 390/03 "dispõe sobre a negociação, por companhias abertas, de ações de sua própria emissão, mediante operações com opções", além de alterar dispositivos da Instrução CVM $n^{\circ}$ 10/80, e revogar as Instruções CVM n ${ }^{\circ} 290$, de 11 de setembro de 1998, e n ${ }^{\circ} 291$, de 25 de setembro de 1998, que regulavam anteriormente o tema.
} 
O segundo capítulo introduzirá o exame das operações de aquisição de ações de emissão própria, com ênfase na análise legal do tema. Após a definiçãa do instituto, abordaremos certos posicionamentos que tratam da possibilidade de companhias recomprarem suas ações, assim como da respectiva manutenção das ações em tesouraria, traçando ainda o cenário da evolução legislativa da operação no Brasil. Trataremos, também, das principais causas para a realização das operações, e dos atos e efeitos relacionados à recompra - aquisição, manutenção, cancelamento e posterior alienação das ações. Com esta análise, pretendemos descrever o cenário legal da operação, referindo-nos aos dispositivos aplicáveis à realização da operação por sociedades anônimas abertas e fechadas. Por fim, no segundo capítulo, passaremos pelas restrições legais aplicáveis à operação, que delimitam os recursos da companhia que podem ser utilizados, protegem o capital social, e limitam a realização de operações por companhias abertas, que serão o foco de nossa análise a partir do capítulo seguinte.

No terceiro capítulo estudaremos especialmente as operações realizadas por companhias abertas. Para que nossa análise não se limite ao exame regulatório do tema, pretendemos desenvolver este capítulo sob a ótica dos principais interesses envolvidos na operação: os interesses da companhia, os interesses dos acionistas, os interesses dos investidores e os interesses dos credores da companhia. Como já referido, a Lei das S.A. se preocupou primordialmente com os interesses dos credores, mas buscaremos demonstrar e analisar a posição de outros agentes que também serão diretamente influenciados pelas operações, e as implicações decorrentes de tais relações. Neste capítulo serão examinadas as principais vedações impostas pelas normas da CVM à realização das operações, a delegação de poderes para que o conselho de administração aprove a recompra de ações, assim como os limites a serem observados pela companhia aberta na realização de operações. Trataremos também das obrigações de divulgação da operação e, por fim, abordaremos a possibilidade de negociação com opções lastreadas em ações de emissão da própria companhia. Buscaremos realizar nosso estudo neste capítulo terceiro sob a ótica de precedentes já examinados pela CVM.

Por fim, o quarto capítulo analisará as consequências da realização de aquisições irregulares por companhias abertas, abrangendo a nulidade das operações, as penalidades administrativas e a responsabilidade imputável aos administradores e acionistas controladores da companhia pela aprovação a negociação ilegal. Apesar de 
menos extenso que os capítulos segundo e terceiro, optamos por dar destaque aos efeitos e possíveis resultados das operações irregularmente realizadas em um capítulo próprio, tendo em vista a importância do tema.

O capítulo quinto tratará da conclusão de nossos estudos, e será seguido pela bibliografia consultada para o desenvolvimento do presente trabalho.

\section{I.2. Negociação com as ações de própria emissão}

Sob o título "Negociação com as Próprias Ações", a Lei das S.A. introduziu o art. 30, que proíbe que a companhia negocie com ações de sua própria emissão. Ao reproduzir tal vedação, anteriormente presente no art. 15 do Decreto-Lei $n^{0}$ 2.627/40, que regulava as sociedades por ações até a entrada em vigor da lei de 1976, o legislador procurou garantir a fixidez e a intangibilidade do capital social da companhia, com o intuito de proteger os credores sociais. Buscaremos, no presente item, iniciar a análise da vedação para que as companhias negociem com as ações que emitir.

\section{I.2.1. A abrangência do termo negociar}

Dispõe o caput do art. 30 da Lei das S.A. que "a companhia não poderá negociar com as próprias ações". O termo "negociar"9 - e suas variações, como "negociação" - foram empregados em outros artigos da Lei das S.A. e, apesar de possuírem sentido bastante amplo, não tiveram os seus limites legalmente definidos ${ }^{10}$.

Especialmente quanto à previsão do caput do art. 30, entendemos que o dispositivo explicitaria melhor seus objetivos se vedasse à companhia negociar com "as ações de sua própria emissão". Isso porque a expressão "negociar com as próprias ações" é imprecisa, tendo em vista que a sua interpretação exata abrangeria também

\footnotetext{
9 "Negociar. 1. Direito Comercial. a) Comerciar; b) comprar e vender com intuito de lucro; c) praticar ato de comércio ou realizar operação mercantile. 2. Direito civil. a) Concluir contrato; contratar; b) ajustar; c) convencionar.” Diniz, Maria Helena. Dicionário Jurídico. Vol. 3. Saraiva: São Paulo. 1998. p. 346.

${ }^{10}$ A utilização do termo "negociação" pela Lei das S.A. para se referir à negociação de ações em bolsa ou mercado de balcão não traz questionamentos quanto a sua abrangência. Veja-se, por exemplo, o art. $4^{\circ}$ da Lei das S.A., que refere-se à "negociação no mercado de valores mobiliários", ou o $\S 4^{\circ}$ do art. 118 , que menciona as ações "negociadas em bolsa ou no mercado de balcão".
} 
quaisquer ações de outras sociedades anônimas detidas pela companhia, igualmente consideradas próprias. De qualquer forma, o objetivo do legislador ao tratar do tema sempre foi conhecido, e com uma leitura histórica não há dúvidas de que não se pretendeu abranger as ações de propriedade da companhia com o fito de participar de terceiras sociedades que fossem de sua conveniência.

José Luiz Bulhões Pedreira, co-autor do anteprojeto da Lei das S.A., auxilia-nos esclarecendo que ao prever que a companhia não poderá negociar com as próprias ações, pretendeu-se vedar a celebração de qualquer negócio jurídico realizado com o objetivo de permitir a circulação da propriedade das ações. Desta forma, buscou-se proibir que a companhia celebre "negócios jurídicos: (a) pelos quais adquira as próprias ações, salvo nos casos constantes do $\S 1^{\circ}$ do artigo em que a aquisição é expressamente admitida; e (b) aliena as próprias ações, exceto as que tenham sido validamente adquiridas para serem mantidas em tesouraria.". Consequentemente, os negócios jurídicos inicialmente vedados pelo caput do art. 30 são que possuem como objetivo a transmissão da propriedade das ações, ou seja, a compra e venda, a permuta, a doação e a dação em pagamento que não respeitem os limites legais, desde que não estejam enquadrados nas exceções descritas no $\S 1^{\circ}$ do mesmo artigo ${ }^{11}$.

É possível, ainda, observar outras disposições da Lei das S.A. em que o termo negociar foi empregado em sentido semelhante ao pretendido no caput do art. 30 . Destacamos, exemplificativamente, o art. 29 da Lei das S.A., que trata da negociabildade das ações, e estabeleceu que "as ações da companhia aberta somente poderão ser negociadas depois de realizados $30 \%$ (trinta por cento) do preço de emissão". Empregando-se aqui o disposto acima, entendemos que as ações da companhia aberta somente poderão ter sua propriedade transmitida após a integralização de parte de seu preço de emissão, por tratar-se de obrigação pessoal assumida pelo subscritor perante a companhia. Não podem, portanto, antes da referida integralização parcial ser alienadas, permutadas, doadas ou dadas em pagamento pelo subscritor inicial.

\footnotetext{
${ }^{11}$ Lamy Filho, Alfredo. Bulhões Pedreira, José Luiz. A Lei das S.A. Pareceres. Vol. II. $2^{\mathbf{o}}$ Ed. Rio de Janeiro: Renovar. 1996. p. 595.
} 
Desta forma, é possível entender que a vedação pretendida pelo art. 30 da Lei das S.A. relaciona-se ao direito de transmitir livremente as ações de emissão própria de forma onerosa ou gratuita, ressalvadas as exceções legais. A proibição inicial à negociação trata, assim, de exceção à regra geral de que "a propriedade do título compreende a faculdade dele dispor" ${ }^{\prime 2}$, já que as transferências das ações de um terceiro para a própria companhia, e da companhia para um terceiro, deve observar as restrições legais.

Por fim, dentre as exceções legais à proibição de negociar previstas no $\S 1^{\circ}$ do art. 30 da Lei das S.A., o resgate, o reembolso, a compra de ações em bolsa para redução do capital social, e a aquisição e a alienação das ações em tesouraria são operações que resultam na transferência da propriedade das ações envolvidas. Já a amortização, como veremos, não resulta na circulação das ações, mas apenas na transferências para os acionistas, a título de antecipação, de certas quantias que lhes seriam devidas no caso de liquidação da companhia, remanescendo inalterada a propriedade das ações.

\section{I.2.2. Aparente vedação}

A leitura isolada do caput do art. 30 da Lei das S.A. sugere que a proibição para as companhias abertas negociarem com as ações de sua própria emissão trata-se de vedação absoluta. Contudo, como se sabe, os artigos devem ser analisados dentro de um sistema que se articula logicamente, o que demanda, além do exame gramatical, uma interpretação lógico-sistemática, que não pode ser realizada através da apreciação de partes independentes da lei ${ }^{13}$.

$\mathrm{O}$ art. 30 da Lei das S.A., portanto, deve ser analisado em sua completude. A partir de seu exame é possível depreender que seus parágrafos possuem duas funções, pois modificam o disposto no caput (parágrafo primeiro), e explicam suas disposições (parágrafos segundo a quinto) $)^{14}$.

\footnotetext{
${ }^{12}$ Bulhões Pedreira, José Luiz. Lamy Filho, Alfredo. Direito das Companhias. Vol. I. Rio de Janeiro: Editora Forense. 2009. p. 522.

${ }^{13}$ Reale, Miguel. Lições Preliminares de Direito. 17a. edição. São Paulo: Saraiva. 1990. pp. 275.

${ }^{14}$ Mendes, Gilmar. Questões Fundamentais de Técnica Legislativa in Revista Eletrônica sobre a Reforma do Estado. Número 11. Salvador. 2007. p. 8.
} 
Interessam-nos, neste ponto, as disposições do parágrafo primeiro do art. 30, que alteram de forma substancial a proibição inicial de que uma companhia não pode negociar com as ações de sua própria emissão, trazendo as exceções à regra de caráter geral do caput. Traçaremos, a seguir, breves comentários a respeito das exceções à vedação de ordem geral previstas nas alíneas "a" e "d" do $\S 1^{\circ}$ do art. 30 da Lei das S.A., procurando destacar sinteticamente as respectivas diferenças entre tais operações e a recompra de ações, que será objeto de nossa análise a partir do segundo capítulo do presente trabalho.

\section{I.2.3. Outras negociações autorizadas}

Como já referido, além da aquisição e da alienação de ações mantidas em tesouraria, a Lei das S.A. previu a negociação pela companhia com ações de sua própria emissão nas operações de resgate, amortização, reembolso ou compra quando, resolvida a redução do capital social através de restituição, em dinheiro, de parte do valor das ações, o preço destas em bolsa for inferior ou igual ao montante a ser restituído. Passaremos, brevemente, por certas semelhanças e diferenças existentes entre tais operações e as operações de recompra de ações.

Quanto à operação de resgate, sua definição foi dada pela própria Lei das S.A. O $\S 1^{\circ}$ do art. 44 trata o resgate como "o pagamento do valor das ações para retirá-las definitivamente de circulação, com redução ou não do capital social" e, "mantido o mesmo capital, será atribuído, quando for o caso, novo valor nominal às ações remanescentes".

Visto sob a ótica da companhia, o resgate poderia ter resultado semelhante ao de uma recompra com o subsequente cancelamento pela sociedade das ações recebidas. Isso porque, em ambas as operações, a companhia utiliza-se lucros ou reservas disponíveis para pagar o valor das ações e retirá-las terminantemente de circulação. São, no entanto, operações diversas, pois o resgate é compulsório e dirigido a um universo de ações específicas. Desta forma, caso não abranja a totalidade de uma classe de ações, 
deve ser realizado mediante sorteio (art. $44, \S^{\circ}$ da Lei das S.A.), assemelhando-se, assim, a uma "autêntica expropriação"15.

Nas palavras dos autores da Lei das S.A., o resgate "é negócio jurídico unilateral - é manifestação de vontade apenas da companhia que o delibera, independentemente do consenso do titular da ação resgatada" ${ }^{\text {16 }}$. E, como veremos de forma mais aprofundada ao longo do estudo, na recompra de ações a aceitação da parte que aliena seus títulos é voluntária, ou seja, o acionista opta se deseja ou não alienar as suas ações para a companhia, não havendo, portanto, como conhecer previamente quais serão os acionistas que transferirão as suas ações.

A amortização, por sua vez, encontra-se definida no $\S 2^{\circ}$ do art. 44 da Lei das S.A., como a "distribuição aos acionistas, a título de antecipação e sem redução do capital social, de quantias que lhes poderiam tocar em caso de liquidação da companhia". Trata-se de operação através da qual a companhia utiliza lucros ou reservas disponíveis no pagamento de parte ou da integralidade do que seria devido aos acionistas no caso de sua liquidação. Lembramos, apenas, que a participação dos acionistas no acervo da companhia quando da liquidação é de direito essencial (inciso II do art. 109 da Lei das S.A.) e, desta forma, conforme o $\S 5^{\circ}$ do art. 44, as ações já amortizadas "só concorrerão ao acervo líquido depois de assegurado às ações não amortizadas valor igual ao da amortização, corrigido monetariamente" na ocorrência da liquidação.

Apesar de ser forma de transferência de recursos para o acionista de uma companhia, assim como tendo em vista que não reduz o capital social, a amortização não resulta na transferência da propriedade das ações, não possuindo, portanto, procedimentos ou resultados semelhantes ao das operações de recompra de ações. Como referido, é a única exceção prevista no $\S 1^{\circ}$ do art. 30 da Lei das S.A. em que o acionista permanece como proprietário das ações.

\footnotetext{
${ }^{15}$ Comparato, Fábio Konder. Funções e Disfunções do Resgate Acionário in Direito Empresarial. São Paulo: Saraiva. 1995. p. 129.

${ }^{16}$ Bulhões Pedreira, José Luiz. Lamy Filho, Alfredo. Direito das Companhias. Vol. I. Rio de Janeiro: Editora Forense. 2009. p. 265.
} 
Já na operação de reembolso, a companhia paga o valor de suas ações aos acionistas dissidentes de deliberação da assembleia geral. O direito de retirada ou recesso, como também é conhecido o reembolso, trata-se de direito essencial do acionista (art. 109, inciso V da Lei das S.A.), e não funciona como uma sanção para a companhia - é o direito outorgado ao acionista de optar por permanecer em na companhia com condições diferentes de quando adquiriu sua participação. Não é qualquer dissidência que confere o direito de recesso ao acionista, estando as hipóteses expressamente previstas em lei.

A aquisição de ações pela companhia decorrente do exercício do direito de recesso dos acionistas pode ter resultados semelhantes ao de uma recompra de ações, já que o $\S 5^{\circ}$ do art. 45 da Lei das S.A. previu que o valor de reembolso poderá ser pago à conta de lucros ou reservas, exceto a legal, além de reconhecer a possibilidade das ações reembolsadas permanecerem em tesouraria. No entanto, o reembolso pode causar a redução do capital social da companhia, na hipótese dos acionistas, cujas ações forem reembolsadas à conta do capital social, não serem substituídos no prazo de 120 dias $\left(\$ 6^{\circ}\right.$ do art. 45 da Lei das S.A.) ${ }^{17}$. Trata-se de diferença substancial com a operação de recompra de ações, tendo em vista ser princípio basilar desta última a manutenção do capital social da companhia.

As operações de reembolso e recompra diferem, ademais, porque a obrigação de reembolsar as ações do acionista dissidente torna-se em princípio compulsória para a companhia, decorrente apenas de manifestação tempestiva e unilateral de vontade $^{18}$, e a recompra de ações resulta da conciliação de vontades da companhia e do acionista alienante. Contudo, a possibilidade de utilização das ações de emissão própria recebidas pela companhia para permanência em tesouraria, seja através de reembolso, seja através de recompra, não difere ${ }^{19}$.

\footnotetext{
${ }^{17}$ Lamy Filho, Alfredo. Bulhões Pedreira, José Luiz. A Lei das S.A. Pareceres. Vol. II. $2^{\circ}$ Ed. Rio de Janeiro: Renovar. 1996. p. 594. Carvalhosa, Modesto. Comentários à Lei de Sociedades Anônimas. $1^{\circ}$ Volume. $6^{\mathrm{a}}$ edição. São Paulo: Saraiva. 2011. pp. 544-545.

${ }^{18} \mathrm{Na}$ forma do $\S 3^{\circ}$ do art. 137 da Lei das S.A., a companhia poderá ratificar ou reconsiderar a deliberação desencadeadora do direito de recesso se entender que o pagamento do preço do reembolso das ações porá em risco a estabilidade financeira da empresa.

19 Apesar do art. 45 da Lei das S.A., desde a sua redação inicial em 1976, prever a possibilidade da manutenção em tesouraria de ações recebidas pela companhia por conta da operação de reembolso, o art. $30, \S 4^{\circ}$ da mesma lei previu que apenas as ações adquiridas através de recompra, enquanto mantidas em tesouraria, não terão direito a dividendo nem a voto. No entanto, como veremos ao longo deste trabalho, a
} 
A última exceção a que faremos referência neste item trata-se da compra de ações prevista na alínea $\mathrm{d}, \S 1^{\circ}$, do art. 30 da Lei das S.A. A operação ocorre quando, resolvida a redução do capital social mediante restituição, em dinheiro, de parte do valor das ações, o preço destas em bolsa for inferior ou igual à importância por ação que seria restituída com a redução do capital. Nesta operação será aprovada a redução de capital da companhia pela assembleia geral com pagamento em dinheiro, à vista. A deliberação definirá o valor da redução e a quantidade de ações a serem canceladas com a operação. Em seguida, caso o preço em bolsa da mesma quantidade de ações for inferior ou igual ao montante da redução do capital social pretendido, a companhia poderá decidir pela compra das ações em bolsa para o respectivo cancelamento.

A compra de ações prevista na alínea d do $\S 1^{\circ}$, do art. 30 da Lei das S.A. pode possuir resultados semelhantes ao da recompra, principalmente quando a recompra for realizada por uma companhia aberta em bolsa para o cancelamento das ações adquiridas. O objetivo das operações, contudo, diferem substancialmente, pois a compra visa à redução do capital social, que não pode ser alterado pela recompra de ações. A motivação para a realização das operações também difere, pois a redução do capital social ocorre para sanar uma perda, até o montante dos prejuízos acumulados, ou caso a companhia julgue seu capital excessivo.

Assim, apesar de certas semelhanças existentes entre as operações acima descritas e a recompra de ações, predominam as diferenças, principalmente quanto às motivações que levam uma companhia a realizar cada uma delas. Lembramos, por fim, que as principais causas para que uma companhia decida recomprar suas ações serão estudadas adiante, no item II.2. deste trabalho.

\section{I.3. Escolha e delimitação do tema}

Quando, em 2008, buscávamos um tema de estudo para apresentar pela primeira vez o projeto de ingresso no Programa de Mestrado da Faculdade de Direito da

companhia não torna-se acionista de si própria ao manter suas ações em tesouraria e entendemos, portanto, que aplicam-se às ações adquiridas por reembolso, e mantidas em tesouraria, as mesmas restrições relativas às ações de emissão própria adquiridas para tanto. 
Universidade de São Paulo, a recompra de ações por companhias abertas nos instigou. Estávamos em meio à crise financeira que se alastrou pelos mercados globais a partir de meados de 2007, e que teve início no mercado imobiliário de risco dos Estados Unidos (subprime). A crise na economia global não deixou de afetar o Brasil, servindo como estímulo para que várias companhias abertas brasileiras lançassem programas de reaquisições compensatórias de seu próprio capital, utilizando-se de recursos disponíveis. Isso porque a aquisição de ações de emissão própria é uma forma da administração da companhia demonstrar para o mercado que considera que suas ações estão sub-valorizadas.

O aumento do número de operações realizadas por companhias abertas fez com que surgissem os mais variados questionamentos relacionados, e muitos deles foram colocados para análise pela CVM. Assim, a busca de meios para conciliar a utilização da operação com a realidade do mercado de capitais, levando-se em consideração todos os interesses envolvidos, despertou-nos para o tema. Em seguida, consideramos também para a nossa opção a escassez de estudos organizados sobre a recompra de ações no Brasil, havendo, inclusive, certa carência de doutrina nacional sobre o assunto.

A escolha feita, a nosso ver, se mostrou acertada até os dias de hoje pois, como procuraremos demonstrar ao longo do presente trabalho, há questões variadas, relevantes e interessantes relacionadas à operação de aquisição de ações de sua própria emissão por sociedades anônimas. Apesar do trabalho ter como ênfase o exame da operação descrita em apenas uma alínea de um parágrafo de um artigo da Lei das S.A. (alínea "b", do $\S 1^{\circ}$ do art. 30), encontramos desdobramentos interessantes e atuais ao longo de nossa pesquisa que possibilitaram o desenvolvimento do presente estudo.

Por se tratar de pesquisa a ser desenvolvida para a elaboração de dissertação em mestrado de direito comercial, algumas limitações se impõem. Assim, por mais que a recompra de ações por companhias abertas apresente diversas facetas, não serão desenvolvidas aquelas que escapam ao exame jurídico do tema, tais como análises contábeis ou abordagens econômicas. Entretanto, por se tratar de tema ligado ao mercado de capitais, certos aspectos econômicos deverão ser mencionados, mas apenas com o intuito de compreensão de institutos jurídicos. Nosso objeto de estudo estará nas questões relacionadas ao direito comercial e seus princípios, mesmo tendo o tema 
relação com outras áreas do direito, como o direito tributário e penal, mas que não serão analisadas.

Ademais, faremos referência às operações efetuadas por sociedades anônimas fechadas, tendo em vista serem os mesmos os dispositivos legais que tratam das operações realizadas por companhias abertas e companhias fechadas, mas não será realizada qualquer análise sobre a possível realização de operações de recompra de quotas por sociedades limitadas.

Por fim, as demais formas de negociação com ações de emissão própria por companhias abertas autorizadas pelo $\S 1^{\circ}$ do art. 30 da Lei das S.A. não estarão abrangidas pela presente pesquisa, e apenas foram apresentadas no início do trabalho quando abordado o contexto da proibição geral para que as companhias negociem com as ações de própria emissão. 


\section{Conclusão}

A compreensão do porquê a lei optou por autorizar que uma sociedade anônima adquira ações de sua própria emissão foi uma das motivações que nos fizeram escolher o presente tema para estudo. Isso porque, em um primeiro momento, a operação de recompra de ações aparenta um contra-senso, tendo em vista a autofagia resultante da aquisição de ações de emissão própria. É certo, entretanto, que a companhia que recompra ações não torna-se acionista de si própria.

Ao longo de nossa reflexão, contudo, concluímos que o melhor questionamento a ser realizado não seria o porquê da opção legislativa, mas sim o contrário: porque uma companhia não deveria adquirir ações de sua própria emissão? Assim, sob a influência desta questão procuramos desenvolver nosso trabalho, buscando demonstrar a importância e os benefícios que a operação de recompra de ações pode ter na estruturação de capital e na organização interna de uma sociedade anônima. A despeito do comando geral inicialmente proibitivo, procuramos guiar nosso estudo de forma a elevar o aproveitamento das ações de própria emissão mantidas em tesouraria em prol da companhia emissora, tendo em vista as ações recompradas serem bens de titularidade da companhia.

Cabe, neste sentido, uma análise crítica da disposição constante do caput do art. 30 da Lei das S.A., que estabelece a vedação inicial para, em seguida autorizar que a companhia negocie com suas próprias ações das formas mais variadas. A redação do caput fica ainda fragilizada quando comparamos a abrangência do termo "negociação" com o que entendemos que o legislador buscou ao dispor sobre a possibilidade de aquisição de ações de emissão própria (alínea "b" do $\S 1^{\circ}$ do art. 30). Com base no exame realizado principalmente nos itens I.2.1. e II.1. do presente trabalho, inferimos que os termos "negociação" e "aquisição" foram utilizados no art. 30 da Lei das S.A. com propósitos bastante semelhantes, ou seja, referem-se à celebração de negócios jurídicos que possuam como objeto a transmissão da propriedade das ações.

A redação do art. 30, portanto, poderia ser revista para melhor refletir o panorama atual da negociação por sociedades anônimas com ações de emissão própria. 
Entendemos que a lei exporia melhor seus objetivos sem a vedação inicial à negociação com ações de emissão própria, ou seja, permitindo diretamente a aquisição de tais ações, assim como autorizando as demais exceções constantes do $\S 1^{\circ}$ do art. 30 da Lei das S.A. No que tange especialmente à recompra de ações, poderiam ser conservadas as restrições relativas à utilização de recursos disponíveis das companhias nas operações, bem como à proteção do mercado de capitais contra a criação de condições artificiais de oferta, demanda e cotações das ações, e manipulação de mercado. Especialmente no que se refere à proteção ao capital social, mesmo considerando que este não representa garantia relevante para os credores sociais - como analisado no item II.7.1. - não é possível ignorar que o direito brasileiro adotou seu instituto, seguindo os moldes do direito continental europeu. Desta forma, a conexão da recompra de ações com o princípio da intangibilidade do capital social está de acordo com a organização sistemática da Lei das S.A.

Ademais, por conta das escassas disposições legais sobre a recompra de ações, entendemos que a melhor opção a ser adotada por companhias fechadas para a prevenção de conflitos trata-se da delimitação do tratamento a ser conferido para as operações no estatuto social das companhias. Já as companhias abertas, por sua vez, possuem tratamento mais detalhado, tendo em vista que devem respeitar as regras expedidas pela CVM sobre o tema, na forma do $\S 2^{\circ}$ do art. 30 da Lei das S.A. Tal atribuição de poderes tem como objetivo principal a proteção do mercado de capitais.

Especialmente quanto às companhias abertas, a CVM estipulou limites e vedações para a realização de operações no intuito de preservar os investidores e evitar a manipulação do preço das ações. Nossa análise foi realizada sob o foco dos principais interesses envolvidos nas operações de recompra de ações, considerando principalmente que as normas expedidas pela CVM podem ser revistas para atender ao dinamismo do mercado. É certo, de tal modo, que o interesse da economia nacional deve estar sempre no topo dos interesses protegidos. Ademais, todas as operações devem ser aprovadas e atender aos interesses da companhia, restando, em seguida, a função de conciliar os interesses dos acionista, investidores e credores sociais. A CVM preocupa-se também, ao atuar como regulador de condutas, com a publicidade e a correta divulgação de informações sobre as operações. Eventuais abusos ou descumprimentos das normas 
expedidas pela autarquia devem ser devidamente apurados e punidos no exercício legal de suas funções fiscalizadora e sancionadora.

Estas foram, em síntese, nossas considerações finais sobre o presente trabalho, que teve como principal proposta dissertar a respeito das operações de recompra de ações realizadas por companhias abertas. Adotando posicionamentos em geral favoráveis à utilização de tais operações por sociedades anônimas, concluímos nosso estudo com a expectativa de ter contribuído para uma reflexão sobre as bases necessárias para o desenvolvimento do instituto no direito brasileiro. 


\section{Bibliografia}

Adamek, Marcelo Vieira Von. Responsabilidade Civil dos Administradores de S/A (e as ações correlatas). São Paulo: Saraiva. 2009.

Albanese, Antonio. Operazioni sulle azioni proprie (e leveraged buy out) nel nuovo diritto societario in Conttrato e impresa. Padova: Cedam. 2007. pp. 353-386.

Alonso, Félix Ruiz. Comentários à Lei das Sociedades por Ações (Lei 6404/76) coord. de Geraldo de Camargo Vidigal e Ives Gandra da Silva Martins. Vol. II. São Paulo: Ed. Resenha Universitária / Instituto dos Advogados de São Paulo, 1980.

Ascarelli, Tullio. Problemas das Sociedades Anônimas e Direito Comparado. São Paulo: Saraiva \& Cia., 1945.

----------. Studi in Tema di Societá. Milano: Giuffrè. 1952.

Azevedo, Antônio Junqueira de. Negócio Jurídico: Existência, Validade e Eficácia. $4^{\mathrm{a}}$. edição. São Paulo: Saraiva. 2002.

Barreto Filho, Oscar. As Operações a Termo Sobre Mercadorias ("Hedging”) in Revista de Direito Mercantil Industrial Econômico Financeiro. n ${ }^{\circ} 29$, São Paulo: Revista dos Tribunais, 1979. pp. 11-27.

Bauermeister, Livinston M. Aquisição das Próprias Ações pela Companhia Emissora. Dissertação de Mestrado Apresentada ao Programa de Pós-Graduação em Direito da Pontifícia Universidade de São Paulo - PUC-SP, orientação do Prof. Doutor Fábio Ulhoa Coelho. São Paulo, 2008.

Bevilaqua, Clovis. Código Civil dos Estados Unidos do Brasil. Vol. I. Edição Histórica. Rio de Janeiro: Editora Rio. 1975.

Black, Barbara. Corporate Dividends and Stock Repurchase. Thomson Reuters, 2010. 
Borba, José Edwaldo Tavares. Direito Societário. Rio de Janeiro: Renovar. 2003.

Borchardt, Klaus-Dieter. O ABC do Direito da União Européia. Luxemburgo: Serviço das Publicações da União Européia. 2011, disponível para consulta em http://eurlex.europa.eu/pt/editorial/abc.pdf, acessado em 6 de novembro de 2012.

Bulgarelli, Waldirio. Anulação de Assembléia Geral de Sociedade Anônima; Assembléias Gerais Posteriores - Abuso de Minoria (Parecer) in Revista dos Tribunais. São Paulo. Ano 67. Vol. 514. agosto/1978. pp. 57-64.

Bulgarelli, Waldirio. Manual das Sociedades Anônimas. 5² Ed., São Paulo: Atlas, 1988.

Bulhões, Carlos Eduardo. Estudo sobre o artigo 30 da Lei das S/A. in Opiniões Jurídicas, Rio de Janeiro: Forense, 2002, pp. 27-54.

Bulhões Pedreira, José Luiz. Finanças e Demonstrações Financeiras da Companhia. Rio de Janeiro: Forense, 1989.

Campos, Luiz Antônio de Sampaio. Utilização do Lucro do Exercício: Dividendo e Recompra in Temas de Direito Societário e Empresarial Contemporâneos. São Paulo: Malheiros Editores. 2011.

Cantidiano, Luiz Leonardo. Reforma da Lei das S.A. Comentada. Rio de Janeiro: Renovar, 2002.

Carvalhosa, Modesto. Comentários à Lei de Sociedades Anônimas. $1^{\circ}$ Volume, $6^{\mathrm{a}}$ edição. São Paulo: Saraiva, 2011.

Comentários à Lei de Sociedades Anônimas. $2^{\circ}$ Volume, $4^{\mathrm{a}}$ Ed. São Paulo: Saraiva, 2009. 
. Comentários à Lei de Sociedades Anônimas. $4^{\circ}$ Volume, tomo II, $3^{\text {a }}$ Ed. São Paulo: Saraiva, 2003.

Comissão de Valores Mobiliários - CVM. Projeto de Normatização $\mathrm{n}^{0}$ VIII: Regulamentação da Aquisição das Próprias Ações pela Companhia (ações em tesouraria). Coordenação da Superintendência Jurídica. Rio de Janeiro, 1979.

Comparato, Fábio Konder. Aspectos Jurídicos da Macro-Empresa. São Paulo: Editora Revistas dos Tribunais, 1970.

. Funções e Disfunções do Resgate Acionário in Direito Empresarial. São Paulo: Saraiva, 1995, pp. 120-130.

O Poder de Controle na Sociedade Anônima. $3^{\circ}$ Ed. inteiramente rev. atual. e corr., Rio de Janeiro: Forense, 1983.

Correia, A. Ferrer. Acções Adquiridas pela Própria Sociedade Emitente e Direito de Voto in Estudos de Direito Civil Comercial e Criminal. Coimbra: Livraria Almedina., 1985, pp. 121-127.

Costa, Judith Hofmeister Martins. A Teoria da Causa em Perspectiva Comparativista: a Causa no Sistema Civil Francês e no Sistema Civil Brasileiro in AJURIS, Porto Alegre, v. 16 , n. 45. pp. 213-244.

Costa, Philomeno J. da. Operações da Anônima com as Ações do seu Capital. São Paulo, 1965.

Cueto, Jose Carlos Vazquez. Regimen Jurídico de la Autocartera. Madrid: Marcial Pons, Ediciones Jurídicas, S.A. 1995.

Davies, Paul L. Principles of Modern Company Law. Seventh Edition. London: Sweet \& Maxwell, 2008.

Diniz, Maria Helena. Dicionário Jurídico. Vol. 3. Saraiva: São Paulo. 1998. 
Dittmar, Amy K. Why Do Firms Repurchase Stock? in The Journal of Business. Vol. 73. N $1^{\circ}$. 3 (Jul., 2000), pp. 331-355, disponível para consulta em http://www.jstor.org/stable/2668568?origin=JSTOR-pdf\&, acessado em 2 de novembro de 2012.

Domingues, Paulo de Tarso. Do Capital Social. Noção, Princípios e Funções. Coimbra: Coimbra Editores. 1998.

Eizirik, Nelson. A Lei das S/A Comentada. Volume I. São Paulo: Quartier Latin. 2011.

A Lei das S/A Comentada. Volume II. São Paulo: Quartier Latin. 2011.

A Lei das S/A Comentada. Volume III. São Paulo: Quartier Latin. 2011.

Eizirik, Nelson. Gaal, Ariádna B. Parente, Flávia. Henriques, Marcus de Freitas. Mercado de Capitais - Regime Jurídico. Rio de Janeiro: Renovar. 2008.

Ferreira, Waldemar Martins. Instituições de Direito Comercial. Vol. 1. $2^{\mathrm{a}}$ ed. Rio de Janeiro: Livraria Editora Freitas Bastos, 1947.

França, Erasmo Valladão A. e N. Adamek, Marcelo Vieira Von. A Proteção aos Credores e aos Acionistas no Aumento de Capital in Revista do Advogado. São Paulo. Vol. 96. 2008. pp. 32-40.

França, Erasmo Valladão Azevedo e Novaes. A Proteção aos Credores e Acionistas nos Aumentos de Capital Social in Temas de Direito Societário, Falimentar e Teoria da Empresa. São Paulo: Malheiros. 2009. pp. 236.

Gabrielli, Márcio F. Saito, Richard. Recompra de ações e proteção dos minoritários. Disponível para consulta em http://www16.fgv.br/rae/artigos/2207.pdf (acessado em 31 de março de 2011).

Gevurtz, Franklin A. Corporation Law. Second Edition. West. 2010. 
Gomes, Orlando. Contratos. 26a edição. Rio de Janeiro: Forense, 2009.

Orlando. Direitos Reais. 18a edição. Rio de Janeiro: Forense, 2001.

Guerreiro, José Alexandre Tavares. Aquisição de Quotas pela própria Sociedade in Revista de Direito Mercantil Industrial Econômico Financeiro. $\mathrm{n}^{\circ}$ 36, São Paulo: Revista dos Tribunais, 1979. pp. 50-57.

Contratos Coligados, Swap, Vedação de Negociação com as Próprias Ações e Proibição de Comportamento Contraditório in Processo Societário. São Paulo: Quartier Latin, 2012. pp. 317-382.

Regime Jurídico do Capital Autorizado. São Paulo: Editora Saraiva, 1984.

Hertig, Gerard. Kanda, Hideki. Creditor Protection in The Anatomy of Corporate Law. Oxford: Oxford University Press, 2002, pp. 71-99.

Hull, John. Introdução aos Mercados Futuros e de Opções. $2^{\text {a }}$ edição. São Paulo: Bolsa de Mercadorias \& Futuros e Cultura Editores Associados, 1996.

Hungria, Nélson. Comentário ao Código Penal. Volume VII, Rio de Janeiro: Forense, 1955.

International Organization Of Securities Commissions - IOSCO. Report On "Stock Repurchase Programs". Disponível para consulta em http://www.iosco.org/library/pubdocs/pdf/IOSCOPD161.pdf (acessado em 5 de outubro de 2012).

Iudícibus, Sérgio. Martins, Eliseu. Gelbcke, Ernesto Rubens. Santos, Ariovaldo dos. Manual de Contabilidade Societária. São Paulo: Editora Atlas S.A. 2010.

Kalansky, Daniel. Peyser, Luis. Empréstimo de Ações e o Mercado de Capitais in Direito Empresarial, São Paulo: Editora Método, 2005. pp. 19-37. 
Kübler, Friedrich. Derecho de Sociedades (Gesellschaftsrecht). Madrid: Fundación Cultural del Notariado. 2001.

Kucukgungor, M. Asli. Acquisition by a Company of its Own Shares from the Perspective of Capital Maintenance Rules, setembro de 2004, disponível para consulta em http://www.jeanmonnet.org.tr/website/tr/dosyalar/tezler/m_a_kucukgungor.pdf (verificado em 8 de abril de 2008).

Lamy Filho, Alfredo. Capital social - Conceito - Atributos - A Alteração Introduzida pela Lei 9.457, de 1997 - O Capital Social no Sistema Jurídico Americano in Temas de S.A. Rio de Janeiro: Renovar, 2007. pp. 179-187.

Lamy Filho, Alfredo. Bulhões Pedreira, José Luiz. A Lei das S.A. Pareceres. Vol. II, $2^{\circ}$ Ed. Rio de Janeiro: Renovar, 1996.

A Lei das S.A. Vol. I, Rio de Janeiro: Renovar, 1997.

-. Direito das Companhias. Vol. I, Rio de Janeiro: Forense, 2009.

Direito das Companhias. Vol. II, Rio de Janeiro: Forense, 2009.

Lazzareschi Neto, Afonso Sérgio. Lei das Sociedades Por Ações Anotada. 2a edição. São Paulo: Saraiva, 2008.

Leães, Luiz Gastão Paes de Barros. A Negociação com as Próprias Ações por Sociedade Anônima de Capital Aberto in Direito Comercial: Textos e Pretextos. São Paulo: José Bushatsky, 1976. pp. 33-60.

Aquisição de Ações do Próprio Capital para Cancelamento in Pareceres. vol. 1, São Paulo: Editora Singular, 2004. pp. 633-649.

---------. O Direito de Voto de Ações Gravadas com Usufruto Vidual in Pareceres. vol. 2, São Paulo: Editora Singular, 2004. pp. 1357-1368. 
Lutter, Marcus. Legal Capital in Europe. Berlin: Rechtswissenschaften de Gruyter Verlags-GmbH. 2006.

Magalhães, Roberto Barcellos de. A Nova Lei das Sociedades Por Ações Comentada. Vol. 1, Rio de Janeiro: Freitas Bastos, 1977.

Manning, Bayless. Hanks Jr. James J. Legal Capital. Third Edition. New York: The Foundation Press, Inc. 1990.

Martins, Fran. Comentários à Lei das Sociedades Anônimas. Vol. I. Rio de Janeiro: Forense, 1977.

Mendes, Gilmar. Questões Fundamentais de Técnica Legislativa in Revista Eletrônica sobre a Reforma do Estado. Número 11. Salvador. 2007.

Mendonça, José Xavier Carvalho de. Tratado de Direto Comercial Brasileiro. Vol. 2. Tomo 2. $1^{\text {a }}$ ed. Campinas: Bookseller, 2001.

Moraes, Maria Celina Bodin de. A Causa doa Contratos in Revista Trimestral de Direito Civil. vol. 21. jan/mar 2005.

Moreira, Luís Fernando. Procianoy, Jairo Laser. Open Market Stock Repurchases at São Paulo Stock Exchange - Bovespa. 2001. Disponível para consulta em http://papers.ssrn.com/sol3/papers.cfm?abstract_id=274257 (acessado em 9 de maio de 2011).

Nascimento, João Pedro Barroso do. Medidas Defensivas à Tomada de Controle de Companhias. São Paulo: Quartier Latin. 2011.

Neves, Rodrigo Santos. O Princípio da Intangibilidade do Capital Social in Revista Forense, vol. 363, pp. 161-177. 
Nobili, Raffaele. Asservazioni in Tema di Azioni Proprie in Rivista delle Società. Anno 32 (1987). Fascicolo 3-4. Milano: Guiffré Editore. pp. 760-806.

Noronha, Ilene Patrícia de. Poder de Polícia da CVM in Conselho da Justiça Federal, Série Cadernos do CEJ, Simpósio sobre Direito dos Valores Mobiliários. Brasília. 1998, vol. 5. Disponível para consulta em http://www.cjf.jus.br/revista/seriecadernos/VOL15-8.htm (acessado em 22 de novembro de 2012).

Nossa, Silvania Neris. Lopes, Alexsandro Broedel. Teixeira, Aridelmo. A Recompra de Ações e a Análise Fundamentalista: um Estudo Empírico na Bovespa no período de 1994 a 2006 in Brazilian Business Review. Vol. 7. N. 1. 2010. pp. 1-23.

Oliveira, Fernando A. Albino. Poder Regulamentar da CVM. Tese apresentada para Doutoramento em Direito Econômico na Faculdade de Direito da Universidade de São Paulo. Orientador Professor Geraldo de Camargo Vidigal. 1989.

Ottanelli, Oriana. Acquisto di Azioni Proprie e Conseguente Riduzione del Capitale in Rivista Del Diritto Commerciale. Anno LXXXVI (1988). N. 3-4. Roma: Piccin Nuova Libraria S.P.A. pp. 205-232.

Papini, Roberto. Sociedade Anônima e Mercado de Valores Mobiliários. Rio de Janeiro: Forense, 1987.

Pereira, Caio Mário da Silva. Instituições de Direito Civil. Vol. I. 20ª edição. Rio de Janeiro: Forense, 2004.

Pereira, Caio Mário da Silva. Instituições de Direito Civil. Vol. III. 12a edição. Rio de Janeiro: Forense, 2006.

---------. Instituições de Direito Civil. Vol. IV. Rio de Janeiro: Forense, 2006.

Pedreira, José Luiz Bulhões. 25 Anos de CVM in Revista da CVM, n 35. 2002. 
Finanças e Demonstrações Financeiras da Companhia. Rio de Janeiro: Forense. 1989.

Penteado, Mauro Bardawil. O Penhor de Ações no Direito Brasileiro. São Paulo: Malheiros Editores. 2008.

Penteado, Mauro Rodrigues. Aumentos de Capital das Sociedades Anônimas. São Paulo: Saraiva, 1988.

Perin Junior, Ecio. Ações Adquiridas pela Própria Sociedade Emitente e o Direito de Voto Como Forma de Blindagem da Empresa Plurissocietária in Direito Empresarial, São Paulo: Editora Método, 2005.

Pontes, Aloysio Lopes. Sociedades Anônimas. Vol I, $3^{\text {a }}$ edição, Rio de Janeiro: Revista Forense, 1954.

Pontes de Miranda, Francisco Cavalcanti. Tratado de Direito Privado. Tomo V. $3^{\text {a }}$ edição. Rio de Janeiro: Editor Borsoi, 1970.

Reale, Miguel. Lições Preliminares de Direito. 17a. edição. São Paulo: Saraiva. 1990.

Rocha, Maria Victória Rodrigues Ferreira. Aquisição de Acções Próprias No Código das Sociedades Comerciais. Coimbra: Almedina, 1994.

Rock, Edward. Kanda, Hideki. Kraakman, Reinier. Significant Corporate Actions in The Anatomy of Corporate Law. Oxford: Oxford University Press, 2002, pp. 131-155.

Rosman, Luiz Alberto Colonna. Capital Social - Princípios da Realidade e da Intangibilidade - Funções e Disfunções (Aumento de Capital da Petrobrás em 2010 e Determinadas Regras do IFRS) in Direito Societário: estudos sobre a Lei de Sociedades por Ações. São Paulo: Saraiva. 2013. pp. 61-117.

Salles, Marcos Paulo de Almeida. Mercado de Valores Mobiliários e Comissão de Valores Mobiliários - comentários à Lei 6.385/76 coord. de Geraldo de Camargo 
Vidigal e Ives Gandra da Silva Martins. Vol. III. São Paulo: Ed. Resenha Universitária / Instituto dos Advogados de São Paulo, 1980.

O Contrato Futuro. São Paulo: Cultura Editores Associados, 2000.

Santos, Alexandre Pinheiro dos. Osório, Fábio Medina. Wellisch, Julya Sotto Mayor. Mercado de Capitais. Regime Sancionador. São Paulo: Editora Saraiva. 2012.

Souza Júnior. Francisco Satiro de. Regime Jurídico das Opções Negociadas em Bolsas de Valores. Tese apresentada para Doutoramento em Direito Comercial na Faculdade de Direito da Universidade de São Paulo. 2002.

Stuber, Walter Douglas. A Negociação com Opções por Companhia Aberta in Revista de Direito Bancário e do Mercado de Capitais, $\mathrm{n}^{\circ} 23,2004$, pp. 394-396.

Sztajn, Rachel. Futuros e Swaps: uma Visão Jurídica. São Paulo: Cultural Paulista, 1998.

----------. Regulação e o Mercado de Valores Mobiliários in Revista de Direito Mercantil, Industrial, Econômico e Financeiro. $n^{0}$ 135. São Paulo: Editora Malheiros, 2004. pp. 136-147.

Teixeira, Egberto Lacerda. Tavares Guerreiro, José Alexandre. Das Sociedades Anônimas no Direito Brasileiro. Vol. 1, São Paulo: Bushatsky, 1979.

---------. Das Sociedades Anônimas no Direito Brasileiro. Vol. 2, São Paulo: Bushatsky, 1979.

Tepedino,Gustavo. Barboza, Heloísa Helena. Bodin de Moraes, Maria Celina. Código Civil Interpretado conforme a Constituição da República. Vol. 1, Rio de Janeiro: Renovar, 2004.

Trindade, Marcelo. Mútuo de Ações e Insider Trading. No prelo. 
----------. Vedações à Negociação de Valores Mobiliários in Temas de Direito Societário e Empresarial Contemporâneos. São Paulo: Malheiros Editores. 2011.

Valverde, Trajano de Miranda. Sociedades por Ações. Vol. I, Rio de Janeiro: Forense, 1953.

Sociedades por Ações. Vol. II, Rio de Janeiro: Forense, 1953.

Sociedades por Ações. Vol. III, Rio de Janeiro: Forense, 1953.

Ventura, Raul. Auto-Participação da Sociedade: as Acções Próprias. Disponível para consulta em http://www.estig.ipbeja.pt/ ac_direito/RVentura78.pdf e http://www.estig.ipbeja.pt/ ac_direito/RVentura78-2.pdf (acessado em 1 de outubro de 2012).

Wyatt, Michael C. Company Acquisition of Own Shares. Forth Edition. FT Law \& Tax: London. 1995.

Yazbek, Otavio. Regulação do Marcado Financeiro e de Capitais. Rio de Janeiro: Elsevier, 2007. 